\title{
Human Resource Management (HRM) and Information Technology (IT): Some Empirical Evidences in the Context of Saudi Arabia
}

\author{
Razali Bin Mat Zin \\ College of Industrial Management, King Fahd University of Petroleum and Minerals, Saudi Arabia \\ matali@kfupm.edu.sa
}

\begin{abstract}
This research is intended to examine the relationships among the use of IT by organizations, HRM performances on its functional tasks on productivity, efficiency, and cost-effectiveness, organizational performances, the IT implementation gap, HRM transformation gap, and organizational performances gap. The HRM practitioners who are registered as members of Arabian Society of Human Resource Management (ASHRM) were randomly selected as respondents to response to the questions in the questionnaire. All the four hypotheses were statistically supported. The use of IT had significant correlations with the HRM functional performances based on productivity, efficiency, and cost-effectiveness. In addition, the IT implementation gap proved to be significant to the overall performances of HRM functional task. Several practical implications from the research findings and future research agenda were discussed at the end of the report.
\end{abstract}

Keywords: Information Technology; Human Resource Management; Organizational Performance; Correlation Analysis

\section{Introduction}

Researchers and industry experts from both IT and HRM universally agree that nothing is certain for the future of e-HR system, the first wave of innovations is likely to be seen (and already emerging) as an integration of various systems involved in different functional aspect of the HRM (Kehoe, Dickter, Russell \& Sacco, 2005); it is of critical importance because integration usually allow for more convenient, faster and cost-effective service delivery, thus, can maximize the value of an e-HR system for the organizations. Cardy and Miller (2005) report that as the technology has made important strides in allocating human resources to strategic direction or new projects nowadays, separate HRM functions have seen application of software and the development of web-based applications; however, it is "at a more macro level, a level that cuts across and integrates various management functions, where development and corporate funds seem to be focused". They further argue that it is the software system that "integrates across all areas of an organization and captures the entire enterprise seems to wring out all the potential advantages of a technological approach, such as greater speed, clarity, efficiency and improved planning capabilities, among others. For instance, when paired with the e-HR system, the competencies of employees can easily be electronically catalogued, and allows the managers to break down a project into its component tasks and identify the competencies needed for those tasks. Managers then can determine the labor needed, who have the required skills, likely cost, and estimates on time of completion. Alternatively, return-on-investment.

This research will examine the impact of IT utilization by organizations on HRM functional performances namely with regard to productivity, efficiency, and cost-effectiveness, and overall HRM performances. The main purpose of this study is to answer the research questions below:

- What is the relationship between the use of IT and the HRM's functional performances based on productivity?

- What is the relationship between the use of IT and the HRM's functional performances based on efficiency?

- What is the relationship between the use of IT and the HRM's functional performances based on costeffectiveness? 
- What is the relationship between the IT implementation gap and the overall HRM's functional performances?

From a practical perspective, the results of this kind of study will help the HRM practitioners to have a better understanding and appreciation about the dynamics of IT utilization and to what extent it would affect the functional performances of HRM activities. From an academic point of view, this research will add to the scant literature in this topic particularly in the context of Saudi Arabia.

\section{Literature Review}

Numerous studies have attempted to establish the relationship between IT and firm performance. Not all studies have demonstrated a clear payoff from use of IT (Deveraj \& Kholi, 2003; Kohli \& Devaraj, 2003), due in part to the challenge of isolating the IT effect at the organizational level of analysis (Devaraj \& Kohli, 2003; Kelly, 1994). In support of this focus on the HR unit is the fact that organizational constructs vary considerably from one administrative unit to another within the same organization (Pinsonneault \& Kraemer, 1997) and across business units and sites. Therefore, organization-wide investigations are not likely to adequately capture the full range of change that IT may produce. Another issue is the actual measurement of IT. In organizational research, Pinsonneault \& Kraemer (1997) suggested that IT might be conceptualized in terms of the technology itself, the extent of penetration, and the actual use of the technology. As in their investigation, we favored the extent of technology penetration and assessed the pervasiveness of ITsupported HR applications with a comprehensive 78-item inventory. This measurement approach contrasts with previous HRIS and other survey formats that typically enquire about technology or hardware implementation or about the availability of a limited number of applications. Lawler and Morhman's (2003) study, for instance, used a single-item scale to measure the use of HRIS systems with a response format that ranged from "no automation present" to "completely integrated HR information system".

As concluded by Henson (2005) that many studies in this area considered workforce and technology as the "heartbeat and the toolset of the HRM business today", HRM is no doubt the business unit most directly responsible for the managing and the developing of the workforce, while IT is no doubt the enabler for HRM in achieving such goals. Analyzing previous studies related to the impact of IT on HRM, Cardy and Miller (2005) summarized that there are three main reasons for HRM's needs for IT as follows: Firstly, HRM needs IT because of its powerful capability in processing and delivering results in a speedy manner. While resources are getting scarcer, organizations' key to survival and success today lies more and more in speed. With its capability in categorizing, calculating, analyzing, storing, and retrieving, IT can potentially save time and resources by getting work done a lot faster and more accurately. Thus, it is able to free individuals like HRM practitioners and the front line managers, from their cumbersome routine work to concentrate on tasks they are more qualified to perform and can produce added value to the organization. With speed come other competitive advantages associated with HRM's use of IT, such as achieving economies of scale and efficiency (Lawler \& Mohrman, 2003); increased accuracy (Kehoe, Dickter, Russell and Sacco, 2005); minimized cost and strengthened the organizational sustainability to progressively evolve the system to satisfy changing requirements and to capitalize on technology improvements (Cappelli, 2001).

For example, Kozlowski, Toney, Mullins, Weissbein, Brown, and Bell (2001) estimated on-line distance learning can reduce the indirect costs of training (for example, costs associated with travel to training facilities, hotel accommodations for trainees, lost work time for employees attending training) that have estimated to account for 80 percent of overall organizational training expenditures. Cappelli (2001) and Gale (2005) in their studies found that between 70 and 90 percent of large firms nowadays use e-recruiting systems, and it is anticipated that over 95 percent of organizations plan to use them in the near future. In addition, the popular online multi-rater of Computerized Performance Monitoring (CPM) technology (software packages that actually construct evaluation for manager, such as appraisal forms and accompanying narrative sentences and paragraphs by managers' touching screen or clicking buttons) revolutionized the HRM appraisal systems in many organizations leading to a scenario where certain high-tech firms even anticipate they will eventually reach the point where employee evaluations are accomplished entirely online, creating a truly paperless system (Saks, 2008). The second reason for HRM's needs for IT lies in it is capability in handling the complexity of HRM issues. Namely, first, the legal reporting requirements and diverse new 
legislatures requirements; secondly, the novel challenges the current workforce faces. (b) Secondly, a great deal of novel challenges of complexity has surfaced in the workplace due to the drastic changes in working environment, technologies, and the composite of the current workforce. For example, companies like IBM and Kodak now cover trans-related medical care; while 125 Fortune 500 companies now protect transgender employees from job discrimination (Rosenberg, 2007).

Meanwhile, managing depressed workers and managing employee emotions to prevent productivity from dropping had also became an incredibly important part of keeping, recruiting, retaining and developing people. Stern (2006) reported that a famous Lockheed Martin Company in USA which lost total working hours equivalent to USD $\$ 786,000$ contributed by workers who were suffering from depression. With the help of IT, organization such as Lockheed Martin was be able to detect signals, identify potential problematic employee, undergo researches, allocate resources, update related organizational policies and strategies, and communicate more effectively with all members of the organizations to tackle such problem in time. (c) Thirdly, HRM needs IT for its capability in measuring and communicating the overall performances of HRM functions. HRM practitioners have long faced skepticism of not being able to prove that people are the most important asset to the firms. Bell, Lee and Yeung (2006) argued that the root cause to this situation is because HRM's influence on organization's performance is difficult to measure. Drucker (2001) singled out the failure to spell clear objectives for each function as the most serious HRM measurement problem, which eventually led to the inaccuracies in making decisions related to HRM functions. Once all functional and organizational performances get measured with accuracy, HRM practitioners will be able to propose more sophisticated and meaningful human resource analysis. With the off-the-shelf measure software by IT vendors (or by organization itself), HRM organizations and practitioners can now measure and quantify almost any HRM objectives, issues, acts, processes, or activities that can be described in terms of observable variables (Fitz-enz \& Davison 2002). Using IT to measure HRM dimensions can communicate performance expectations in objective quantitative terms, make outcomes more easily understood for the purpose of comparative analysis and benchmarking programs.

\section{Methodology}

Sampling Procedures: In order to assure the quality of the data collected, the researchers themselves distributed the survey to a selected group of human resource management practitioners who are the registered members of the Arabian Society of Human Resource Management (ASHRM). Four hundred fifty members of ASHRM (200 of Jeddah Chapter and 250 of Riyadh Chapter) were randomly selected from the latest membership list to be respondents of this research. The questionnaires were personally distributed and collected during the meetings at each respective location. Since there were no women registered as members of ASHRM, all the respondents were males.

Instrument: The questionnaire were developed and consisted of three main sections: (a) several dimensions on utilization of IT; (b) several dimensions to determine the HRM's functional performances; (c) several dimensions of organizational performances (d) demographic data.

Research Hypotheses: The research hypotheses, which guided this research inquiry, were as follows:

Hypotheses 1: There is a significant relationship between the use of IT and the HRM's functional performances based on productivity. (It was expected that the HRM's functional performances based on productivity is higher when the use of IT is higher).

Hypothesis 2: There is a significant relationship between the use of IT and the HRM's functional performances based on efficiency. (It was expected that the HRM's functional performances based on efficiency is higher when the use of IT is higher).

Hypothesis 3: There is a significant relationship between the use of IT and the HRM's functional performances based on cost-effectiveness. (It is expected that the HRM's functional performances based on the cost-effectiveness is higher when the use of IT is higher).

Hypothesis 4: There is a significant relationship between the IT implementation gap and the overall HRM's functional performances. (It was expected that the overall HRM functional performances is higher when the IT implementation gap is lower). 
Data Collection: Upon receiving the list of memberships from ASHRM Headquarters Office in Dhahran, the researchers randomly selected the respondents for each ASHRM Chapter (Riyadh and Jeddah). In order to expedite the data collection process and receive high response rate, the researchers visited the Annual ASHRAM Meetings, ASHRM Riyadh Chapter Meetings and ASHRM Jeddah Chapter Meetings, which were held on regular basis during the period of March and April 2010. Those selected respondents who attended the Meetings were handed the questionnaires personally and politely requested to fill them immediately.

Data Analysis: The researchers also analyzed, in every research question regarding the use of IT or the HRM's functional performances, the relationship between each IT-related feature in the matrix of the use of IT and the productivity, efficiency, and cost-effectiveness of the HRM's functional performances, and the relationship between each between the performances of each HRM's functional task and, respectively, the use of IT and the organizational performances. With the powerful statistical function of the SPSS 15.0 Full Version, this goal was achieved.

\section{Results}

Reliability Test: The Cronbach's Alpha was used to determine the reliability of the survey instrument with a significance level $>$.70. In general, Cronbach's alpha measures how well a set of items (or variables) measures a single uni-dimensional latent construct; therefore, Cronbach's alpha is not a statistical test, but a coefficient of reliability (or consistency). Cronbach's alpha can be written as a function of the number of test items and the average inter-correlation among the items. Table 1 below presents the results of the reliability analysis for this research.

\section{Table 1: Variables Coefficient alpha}

\begin{tabular}{ll}
\hline Variables & Coefficient alpha \\
\hline Use of IT & .911 \\
HRM Transformation Gap & .949 \\
IT Implementation Gap & .852 \\
HRM Functional Performances - Productivity & .892 \\
HRM Functional Performances - Efficiency & .897 \\
HRM Functional Performances - Cost-effectiveness & .903 \\
Organizational Performances & .873 \\
Overall HRM's Functional Performances & .877 \\
\hline
\end{tabular}

\section{Inferential Statistical Analyses}

Hypotheses 1: There is a significant relationship between the use of IT and the HRM's functional performances based on productivity. It was expected that the HRM's functional performances based on productivity is higher when the use of IT is higher. Hypothesis 1 was supported (Spearman's rho =.668; $\mathrm{p}=$ $0.000 ; \mathrm{N}=450)$. Thus, the correlation is significant at 0.01 (2-tailed) as indicated in Table 2.

Table 2: The Correlation between the Use of IT and HRM Functional Performances Based on Productivity

\begin{tabular}{llllll}
\hline Variables & Mean & Std. Deviation & $\begin{array}{l}\text { Spearman's } \\
\text { coefficient }\end{array}$ & Sig. (2-tailed) & N \\
\hline Use of IT & 3.6141 & .78456 & $.668^{* *}$ & .000 & 450 \\
$\begin{array}{l}\text { HRM Functional } \\
\text { Performances based } \\
\text { on Productivity }\end{array}$ & 3.3988 & .74657 & & & 450 \\
** Correlation is significant at the 0.01 level (2-tailed) & & & \\
\end{tabular}

Hypothesis 2: There is a significant relationship between the use of IT and the HRM's functional performances based on efficiency. It was predicted that the HRM's functional performances based on 
efficiency is higher when the use of IT is higher. The data in Table 3 clearly indicated that the correlation is significant at 0.01 level $(\mathrm{p}=.000)$ with the Spearman's $r$ o coefficient $=.609$

Table 3: The Correlation between the Use of IT and HRM Functional Performances Based on Efficiency

\begin{tabular}{llllll}
\hline Variables & Mean & $\begin{array}{l}\text { Std. } \\
\text { Deviation }\end{array}$ & $\begin{array}{l}\text { Spearman's } \\
\text { rho coefficient }\end{array}$ & Sig. (2-tailed) & N \\
\hline Use of IT & 3.6141 & .78456 & $.609^{* *}$ & .000 & 450 \\
$\begin{array}{l}\text { HRM } \\
\begin{array}{l}\text { Performances based on } \\
\text { Efficiency }\end{array}\end{array}$ & & & & & 450 \\
** Correlation is significant at the 0.01 level (2-tailed) & & & \\
\hline
\end{tabular}

Hypothesis 3: There is a significant relationship between the use of IT and the HRM's functional performances based on cost-effectiveness. Based on this hypothesis it is expected that the HRM's functional performances based on the cost-effectiveness is higher when the use of IT is higher. From the statistical analyses in Table 4, it is found that the correlation is significant at 0.01 level $(\mathrm{p}=.000)$ and the Spearman's rho coefficient $=.533$

Table 4: The Correlation between the Use of IT and HRM Functional Performances Based on Cost Effectiveness

\begin{tabular}{lllllll}
\hline Variables & Mean & $\begin{array}{l}\text { Std. } \\
\text { Deviation }\end{array}$ & $\begin{array}{l}\text { Spearman's } \\
\text { coefficient }\end{array}$ & rho & Sig. (2-tailed) & N \\
\hline Use of IT & 3.6141 & .78456 & $.533^{* *}$ & .000 & 450 \\
$\begin{array}{l}\text { HRM Functional } \\
\begin{array}{l}\text { Performances based on } \\
\text { Cost Effectiveness }\end{array}\end{array}$ & 3.3867 & .75687 & & & 450 \\
** Correlation is significant at the 0.01 level (2-tailed) & & & & \\
\end{tabular}

Hypothesis 4: There is a significant relationship between the IT implementation gap and the overall HRM's functional performances. It was expected that the overall HRM functional performances is higher when the IT implementation gap is lower. The data in Table 5 depicts that Hypothesis 4 was also supported (Spearman's $r h o=.257 ; \mathrm{p}=.000)$.

Table 5: The Correlation between the ITS Implementation Gap and Overall HRM Functional Performances

\begin{tabular}{|c|c|c|c|c|c|}
\hline Variables & Mean & $\begin{array}{l}\text { Std. } \\
\text { Deviation }\end{array}$ & $\begin{array}{ll}\begin{array}{l}\text { Spearman's rho } \\
\text { coefficient }\end{array} & \\
\end{array}$ & Sig. (2-tailed) & $\mathbf{N}$ \\
\hline Use of IT & 4.1469 & .64192 & $.257^{* *}$ & .000 & 450 \\
\hline $\begin{array}{l}\text { HRM Functional } \\
\text { Performances based on } \\
\text { Cost Effectiveness }\end{array}$ & 3.3806 & .70854 & & & 450 \\
\hline
\end{tabular}

Discussions: Several significant and meaningful conclusions could be derived form the of this research including the new role IT and HRM ought to take on, the resolutions to re-align IT and HRM, ownership of IT implementation processes, and the concentration of HRM practices in the future. The research findings of Hypothesis 1 ("There is a significant relationship between the sue of IT and HRM functional performances based on productivity'); Hypothesis 2 ("There is a significant relationship between the use of IT and HRM functional performances based on efficiency"); Hypothesis 3 ("There is a significant relationship between the use of IT and HRM functional performances based on cost-effectiveness"), strongly suggested that IT should be repositioned itself at a higher and more strategic level. The word "just a support function" comes with a 
hierarchical implication, often suggesting a less strategic and less proactive position in tackling environmental challenges. In addition, "support function" is basically a "project" concept-is needed when only is called upon and expected to provide just short-term solutions to "make things work" and blamed when things do not work. Being put in such passive and vulnerable position, it is impossible for IT to ever revolutionize its role and functions, but to perform under its maximal capacity and efficiency. Mead, Shoemaker, and Drommi (2007) states that IT should be deemed as a critical player in "long-term decision making about business direction". Therefore, IT needs to be elevated from the lower and more short-term "support function" level to the more long-term and strategic organizational level in which IT will have to tackle challenges of greater scope and complexity. Only by doing so can, IT is given the opportunity to reevaluate its strengths, re-channel its resources, and engage in business processes more aggressively. This will then transform IT from what it is now as a misplaced and underperformed business force into a "strategic enabler" and an "improvement driver".

The second major conclusion suggested by the research findings is derived from the results of Hypothesis 4 . The findings strongly indicated that misalignment between the use of IT and the overall performances of HRM functions in an organization. However, if IT is transforming the HRM's functional activities is taken out of equation (i.e., existence of IT implementation gap in an organization), a significant correlation between this gap and overall HRM performances is missing. Organizations need to take step to ensure the IT-HRM realignment is well established. Firstly, the efforts through "cross-education" where the practitioners of IT and HRM can learn from each other. More importantly, a mutual respect and appreciation for each other need to be instilled in both practices, with practitioners of both fields staying open-minded as much as possible. Secondly, organizations need to designate more collaborative tasks to HRM and IT practitioners so that both parties can start engaging in a deeper communication and collaborative relationships. Last but not least, top management must recognize that realignment between IT and HRM is a serious on-going process, which deserves long-term commitment. It must be treated as a major agenda in top management's mind. The third major conclusion can be developed from the findings of all the four hypotheses tested in this research. All the findings strongly forced the organizations to seriously consider shifting the HRM practices in the context of a new paradigm. In other words, HRM is facing a difficult turning point. Horizontally, its responsibilities at the functional tasks level are being developed one by one to the departmental line managers facilitated by technological advancements.

Vertically, organizational structure is dissolving and flattened, workforce are diversified. Thus, what HRM has been doing traditionally at the organizational level is changing so rapidly and organizations must be ready to embrace this new wave in the modern era. In this context, HRM in Saudi Arabia in particular needs to redefine its role as quickly as possible in order to avoid being phased out of the business operations of an organization. A practical new paradigm shift is to re-position HRM as the "strategic architect" for the organizations. Responsibilities of such roles will include what has been suggested by Saks (2008): (i) reassessing every aspect of the business to identify potentials and disconnects; rebuild morale; invest in most advanced technical tools to unite company's disparate functions and units; (ii) engage in critical talent acquisition; (iii) apply "coach model" approach in order to enhance a flatter organizational structure and make organizational hierarchy leaner to give tighter focus; (iv) regain the loyalty of the external stakeholders, and (v) establish new modes of working culture. In short, what HRM practitioners need to concentrate in their new roles as "strategic architect" is to sustain a compellingly competitive workforce with diversity of cultures, countries and platforms (Fujimoto, Bahfe, Femelis \& Haurtel, 2007). Many researchers further point out the new focus HRM should concentrate - the knowledge management and the human capital. These two are management enablers that work hand in hand. If the human capital is the framework, knowledge management brings in valuable content.

Human capital emphasizes that people should be deemed as assets that should be valued and developed, not resources that just be consumed." Thus, human capital is the end result of maximizing the value of human resources. For future research, conduct similar survey on IT practitioners in the context of Saudi Arabian other organizations in order to gain a better understanding of IT perspective on the relationships between IT and HRM, and IT and organizational performances. Secondly, conduct comprehensive international study using instrument designed for this research to further investigate the relationship between the use of IT and the HRM performances under different technology density, population density, and geography density. 
Thirdly, conduct researches on the effect of the organizational structure on the relationship between the use of IT and the HRM performances. As the organizational structures in many organizations in Saudi Arabia are experiencing changes in such a drastic manner, the relationship between the use of IT and the HRM performances might differ greatly by industry because of the different organizational structure. Last but not least, conduct research on "outsourcing", both in IT and in HRM. By conducting such research, information and insights can be drawn to explain what really drives the practices of IT and HRM in the outsourcing cycle.

\section{Conclusion}

Information technology (IT) has, of course, changed the face of HRM in many parts of the world. Perhaps the most central use of technology in HRM is an organization's human resources information system (HRIS). Organizations, which are determined to improve productivity and lower costs, considered HR as a good place to start. Since HR functions affect the entire workforce, the impact of HRIS can be dramatic. It can be a potent weapon for lowering administrative costs, increasing productivity, speeding up response times, and improving decision making and customer service.

\section{References}

Bell, B. S., Lee, S. W. \& Yeung, S. K. (2006). The impact of e-HR on professional competence in HRM: Implications for the development of HR professionals. Human Resource Management, 45, 295-308.

Cappelli, P. (2001). Making the most of on-line recruiting. Harvard Business Review, 79, 139-146.

Cardy, R. L. \& Miller, J. S. (2005). E-HR and Performance Management: A consideration of positive potential and the dark side. In Greutal and Stone (Eds.). The Brave New World of e-HR (138-165). San Francisco, CA: Jossey-Bass.

Deveraj, S. \& Kohli, R. (2003). Performance impacts of information technology: Is actual usage the missing link? Management Science, 49, 273-289.

Drucker, P. F. (2001). The essential Drucker. New York, NY: HarperCollins Publishers Inc.

Fitz-enz, J. \& Davison, B. (2002). How to measure human resources management (3rd ed). New York: McGraw-Hill.

Fujimoto, Y., Bahfe, N., Fermelis, J. \& Haurtel, C. (2007). The global village: Online cross-cultural communication and HRM. Cross Cultural Management, 14(1), 7-22.

Gale, S. F. (2005). Making c learning more than pixie dust. Workforce Management, 82, 112-122.

Henson, R. (2005). The next decade of HR: Trends, technologies, and recommendations. In Gueutal and Stone (Eds.), The Brave New World of eHR (255-292). San Francisco, CA: Jossey-Bass.

Kehoe, J. F., Dickter, D. N., Russell, D. P. \& Sacco, J. M. (2005). E-Selection. In Gueutal and Stone (Eds.), The Brave New World of e-HR (54-103). San Francisco, CA: Jossey-Bass.

Kelly, M. (1994). Productivity and information technology: The elusive connection. Management Science, 40, 1406-1425.

Kohli, R. \& Devaraj, S. (2003). Measuring information technology payoff: A meta-analysis of structural variables in firm-level empirical research. Information Systems Research, 14, 127-145.

Kozlowski, S. W. J., Tone U., Mullins, M. E, Weissbein, D. A., Brown, K. G. \& Bell, B. S. (2001). Developing adaptability: A theory for the design of integrated-embedded training systems. In E. Salas (ed.), Advances in human performance and cognitive engineering research, 59-123. Amsterdam: JAI/Elsevier Science.

Lawler, E. E. \& Mohrman, S. A. (2003). HR as a strategic partner: What does it take to make it happened? Human Resource Planning, 26(3), 15-29.

Mead, N. R., Shoemaker, D. \& Drommi, A. (2007). Maintaining its corporate impact through a governance framework. Cutter IT Journal, 20(7), 30-35.

Pinsonneault, A. \& Kraemer, K. (1997). Middle management downsizing: An empirical investigation of the impact of information technology. Management Science, 43, 659-679.

Rosenberg, D. (2007). Rethinking gender. Newsweek, May21, 2007, 50-57.

Saks, D. (2008). Project Rehab. Fast Company, 124, 102-110.

Stern, L. (2006). Get the man to a Monet! Newsweek, October 16, 2006: Enterprise Bytes, E4. 